\title{
Synthesis and Characterization of In-Situ AA8011-TiB 2 Composites Produced by Flux Assisted Synthesis
}

\author{
Muthamizh Selvan Bellamballi Munivenkatappan*, Sathish Shanmugam, Anandakrishnan Veeramani \\ Department of Production Engineering, National Institute of Technology, Tiruchirappalli 620015, Tamil Nadu, India
}

Corresponding Author Email: krishna@nitt.edu

https://doi.org/10.18280/acsm.440505

Received: 2 January 2020

Accepted: 17 August 2020

\section{Keywords:}

aluminium matrix composite, flux assisted synthesis, in-situ stir casting technique, titanium diboride reinforcement, metallurgical studies, mechanical behaviour

\begin{abstract}
In-situ aluminium alloy 8011 matrix composites containing different weight percentages of titanium diboride were synthesized by flux assisted synthesis using stir casting technique. The metallurgy of the in-situ AA8011-TiB 2 composites was analyzed using X-ray diffractometer, scanning electron microscope and energy dispersive spectroscope to disseminate the formation and distribution of reinforcements. Density, microhardness and tensile strength of cast AA8011 and in-situ AA8011-TiB 2 composites were measured and analyzed. The in-situ formed $\mathrm{TiB}_{2}$ reinforcements showed the maximum hardness of 55.03 $\mathrm{Hv}$ and the maximum tensile strength of $158.2 \mathrm{MPa}$ for $8 \mathrm{wt} \%$ of TiB2 whereas the percentage elongation of $7.2 \%$ is observed at 4 wt. $\%$ of TiB2. Further, the fractography analysis performed on the fractured tensile samples and the mechanism of failures were identified and reported.
\end{abstract}

\section{INTRODUCTION}

Metal matrix composites attracted most of the industries as they are versatile to fashion the desired properties. Metal matrix composites remarkably rule the field of material development, in view of producing components with reduced weight and improved properties. Pistons, cylinder liners, valves, pushrods, connecting rods, brake systems, driveshafts, and suspensions are some of the significant applications of metal matrix composites in the automotive sector. Antennas, truss structures, motor casings, nozzles, launch canisters, engine shields, fuel access door covers, and manifolds are some of the specific applications in aerospace industries [1]. Aluminium metal matrix composites offer extensive support in the development of newer composite materials with the desired properties to meet the applications of aerospace and automotive industries [2, 3]. Among the various forms of reinforcements, particulates are observed to be an attractive, economical and easy method to attain an improved hardness and strength. Higher ductility and malleability of AA8011 made it suitable in the application of covering material in automotive body and food packaging industries. Globally the scientific community is attempting to enhance the strength of AA8011 by adding ceramic reinforcements in order to increase the durability and its applications. In the past, only a few researchers have successfully fabricated the composites with AA8011 alloy as a matrix, and the observed findings are as follows. Magibalan et al. produced AA8011 composite with fly ash as reinforcement using stir casting technique and investigated its mechanical and tribological behaviour [4]. Ashok et al. and Vembu et al. synthesized AA8011 aluminium composites with silicon carbide addition using the casting technique to investigate the influence of $\mathrm{SiC}$ on the metallurgical, mechanical and tribological properties $[5,6]$. AA8011 matrix composites with red mud as reinforcement were synthesized by Rao et al. to investigate its mechanical behaviour and reported an improvement in hardness and tensile strength [7]. Latha Shankar et al. synthesized AA8011graphite composites to investigate its mechanical behaviour and observed an increased hardness and tensile strength with the addition of graphite up to 8 wt. \% [8]. Sohi et al. reinforced AA8011 composite with aluminium coated alumina particle through liquid phase surface melting technique and observed a uniform distribution of alumina particle along with an improved hardness [9]. The influence of zirconium diboride addition on the tribological behaviour of in-situ cast AA8011$\mathrm{ZrB}_{2}$ composite was investigated by Muthamizh Selvan et al. $[10,11]$.

It is perceived that reinforcement is the prime factor that enhances the strength of metal matrix composites [1]. Though there are various reinforcements like $\mathrm{TiC}, \mathrm{SiC}, \mathrm{TiB}_{2}, \mathrm{ZrB}_{2}$, $\mathrm{B}_{4} \mathrm{C}, \mathrm{ZrB}_{2}, \mathrm{CrB}$ and $\mathrm{WB}$ are used in strengthening the metal matrix composites, Titanium diboride $\left(\mathrm{TiB}_{2}\right)$ is the most preferred reinforcement due to its unique properties like exceptional hardness, high melting point, good wettability and low cost. Some of the research attempts with the insertion of Titanium diboride as reinforcement are as follows. Titanium diboride reinforced aluminium 6005 composites were synthesized through mechanical alloying technique by AbuWarda et al., and it was observed that the increased alloying time and increased titanium diboride percentage improved the mechanical properties [12]. Insitu Aluminium 7075- $\mathrm{TiB}_{2}$ composite was fabricated using ultrasound-assisted stir casting by Yang et al. and observed an improved hardness with the addition of titanium diboride [13]. Titanium diboride reinforced in-situ aluminium composite was produced by Chen et al. through stir casting and found an improvement in mechanical properties with the addition of titanium diboride [14]. Titanium diboride reinforced in-situ aluminium 6061 composites were fabricated by Kumar et al. through stir casting technique and found an improvement in mechanical properties with the addition of titanium diboride [15]. Shen et 
al. formed in-situ Titanium diboride in Al-Cu-Li matrix and observed improvement in the strength [16]. Likewise, the insitu titanium diboride was formed through the flux assisted technique with the aluminium as matrix and found the improved the mechanical strength, tribological strength and corrosion resistance [17-19]. Apart from $\mathrm{TiB}_{2}$, some of the most common insitu reinforcement synthesied through the flux assited technique are $\mathrm{ZrB}_{2}, \mathrm{TiC}, \mathrm{Al}_{2} \mathrm{O}_{3}, \mathrm{Al}_{3} \mathrm{Ti}$, and $\mathrm{MgAl}_{2} \mathrm{O}_{4}$ [20-22]. Though there are various techniques used to produce metal matrix composites such as casting technique, powder metallurgy [23, 24], and diffusion technique [25] in the past, stir casting technique is mostly preferred owing to its simplicity, flexibility and cost-effectiveness [26]. Also, it is perceived that the formation of in-situ titanium diboride through flux assisted synthesis more effective, efficient and economic. With the above considerations, the present research work attempts to synthesize a novel in-situ cast aluminium alloy $8011-\mathrm{TiB}_{2}$ composites by flux assisted synthesis technique. The paper discus on the novel behavior of the developed insitu AA8011- $\mathrm{TiB}_{2}$ composites in view of its mechanical and metallurgical aspects.

\section{EXPERIMENTAL DETAILS}

The matrix alloy AA8011 is heated in a graphite crucible to a temperature of $850^{\circ} \mathrm{C}$ for 1 hour to attain the complete molten state [10]. To form the titanium diboride reinforcement by flux assisted synthesis using stir casting technique, the appropriate amount of halide salts Potassium hexafluorotitanate $\left(\mathrm{K}_{2} \mathrm{TiF}_{6}\right)$ and Potassium tetrafluoroborate $\left(\mathrm{KBF}_{4}\right)$ were accurately weighed based on stoichiometric calculations, mixed, preheated and added into the molten metal [17]. The exothermic reaction occurs in the melt due to the addition of halide salts induces the formation of titanium diboride in the molten slurry $[18,19]$. To assist the reaction, the formation of $\mathrm{TiB}_{2}$ and uniform distribution of $\mathrm{TiB}_{2}$, the melt was stirred in a regular interval of time of 5 minutes till the end of reaction which is observed by the absence of lightning sparks.

Further, the floating slag is removed, and the melt is poured into the preheated metal molds to obtain the cylindrical composite castings. Following the same procedure, in-situ composites containing 4,8 and 12 weight percentages of $\mathrm{TiB}_{2}$ were produced. In order to study the effect of reinforcement addition, cylindrical castings of pure AA8011 aluminium alloy was also prepared. Samples for metallurgical and mechanical analysis were made from three different castings. While realizing the test samples from $12 \mathrm{wt} . \% \mathrm{TiB}_{2}$ composite, the sample got broken into smaller pieces, and it may be due to the agglomeration $\mathrm{TiB}_{2}$ particles and with higher porosities. Hence the samples are made with the cast AA8011 and AA8011 composites reinforced with 0,4 , and 8 wt. $\% \mathrm{TiB}_{2}$ is considered for further analysis. The density of the cast alloy and composites were measured using a precise weighing balance with a density kit (ACZET CY224C). Samples for metallurgical analysis were mounted, polished and etched as per ASTM standards and the micrographs, and elemental maps were obtained using a Scanning Electroscope Microscope (HITACHI SU 3000). The X-Ray Diffraction analysis was performed using X-Ray Diffractometer (Ultima rigaku III). The hardness of the cast alloy and composites were measured using a micro Vickers hardness testing machine (Wolpert Wilson) with a load of $500 \mathrm{~g}$ for a dwell period of 10 seconds.
Tensile properties of the cast alloy and composites were obtained using $100 \mathrm{kN}$ capacity tensile testing machine (MTS Insight) with a resolution of $0.001 \mathrm{~mm}$ as per ASTM E8/E8M standard. Fractographs of the fractured tensile samples was also obtained using a Scanning Electroscope Microscope, to analyze the mechanism of failure.

\section{RESULTS AND DISCUSSION}

\subsection{Density}

The measured density of cast aluminium alloy 8011 and synthesized in-situ AA8011- $\mathrm{TiB}_{2}$ composites are shown in Table 1. The theoretical density of the cast alloy and composites was calculated using the rule of mixtures, and the same is compared with the measured density, which is very close to the theoretical density. The relative density of three different materials was found to be almost $96 \%$, and rest is the porosity obtained due to gravity casting process.

Table 1. The density of cast AA8011 and in-situ AA8011$\mathrm{TiB}_{2}$ Composites

\begin{tabular}{cccc}
\hline AA8011-x & \multicolumn{2}{c}{ Density } & Relative \\
\cline { 2 - 3 } Wt.\% TiB $_{2}$ & Theoretical & Experimental & Density \\
\hline 0 & 2.710 & 2.590 & 0.9567 \\
4 & 2.782 & 2.690 & 0.9631 \\
8 & 2.855 & 2.716 & 0.9586 \\
\hline
\end{tabular}

\subsection{Metallographic studies}

X-ray diffraction results for synthesized cast AA8011 and in-situ $\mathrm{TiB}_{2}$ reinforced composites are shown in Figure 1, which unveils the presence of aluminium in all the three materials by the appearance of peaks corresponding to aluminium with different Miller indices. Whereas for AA8011- $\mathrm{TiB}_{2}$ composites additional peaks significant to titanium diboride were observed, which confirms the presence of in-situ formed titanium diboride reinforcements in the aluminium matrix. Apart from the peaks of aluminium and titanium diboride, no other significant peaks are observed in the $\mathrm{x}$-ray diffraction analysis. The scanning electron microscopic images shown in Figure 2a clearly shows the microstructure of cast AA 8011 that exhibit the basic structure of the aluminium alloy. The microstructure of the in-situ AA8011-TiB 2 composite with 4 Wt. \% $\mathrm{TiB}_{2}$ shown in Figure $2 \mathrm{~b}$ displays the presence of titanium diboride particle formed in the matrix aluminium. The microstructure of the in-situ AA8011- $\mathrm{TiB}_{2}$ composite with $8 \mathrm{Wt} . \% \mathrm{TiB}_{2}$ is shown in Figure $2 \mathrm{c}$ exhibits the presence of titanium diboride particle in the matrix aluminium. The amount of in-situ titanium diboride present in the $8 \mathrm{Wt}$. \% $\mathrm{TiB}_{2}$ is found to be more than that of in-situ AA8011-4 Wt. \% TiB 2 . From Figure $2 b$, and $2 c$ it is observed that the titanium boride was in-situ formed in AA8011-4 Wt. \% $\mathrm{TiB}_{2}$ and $\mathrm{AA} 8011-8 \mathrm{Wt}$. \% $\mathrm{TiB}_{2}$ with the existence of hexagonal-shaped $\mathrm{TiB}_{2}$, and the same is highlighted using the hexagonal box. The elemental maps obtained for AA 8011- $8 \mathrm{Wt}$ \% $\mathrm{TiB}_{2}$ composite is shown in Figure 3(a-c) which confirms the existence of aluminium, titanium and boride elements in the composite respectively. The merged elemental map is shown in Figure 3d also confirms the presence and uniform distribution of in-situ formed titanium diboride over the AA8011 matrix. 


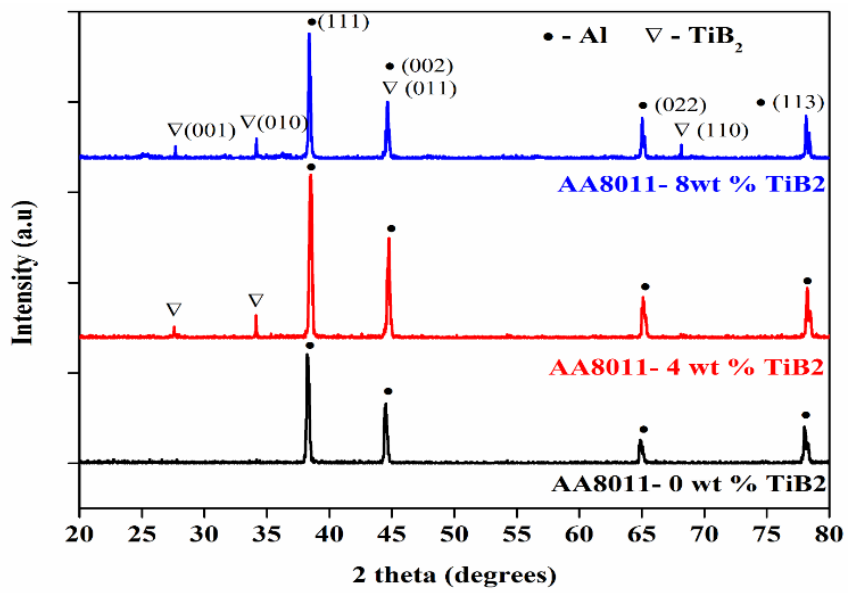

Figure 1. X-ray diffraction patterns of cast AA8011 and insitu AA8011-TiB 2 Composites

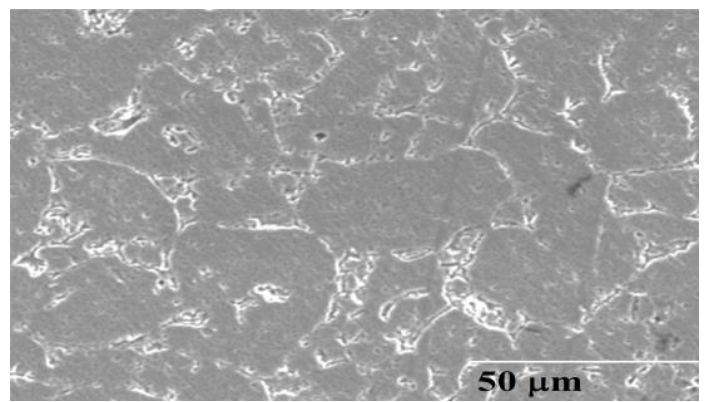

(a) AA8011

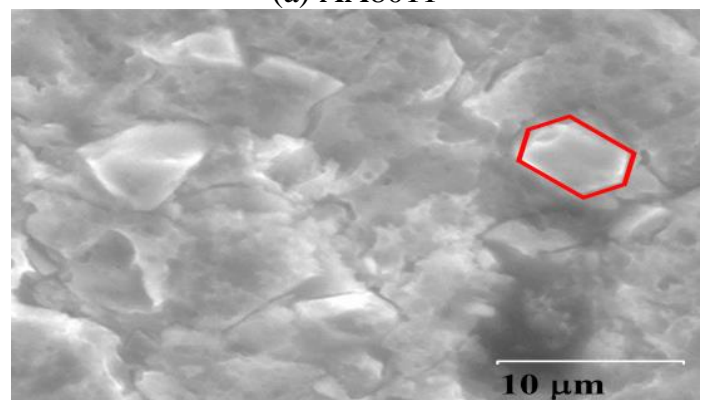

(b) AA8011 - 4 Wt. \% $\mathrm{TiB}_{2}$

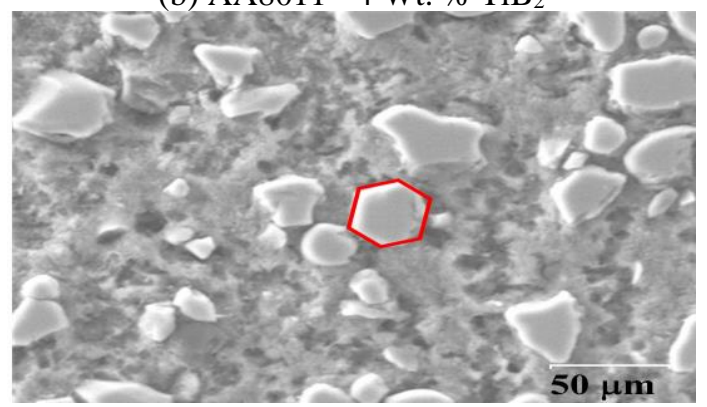

(c) AA8011- 8 Wt. $\% \mathrm{TiB}_{2}$

Figure 2. Composites SEM image

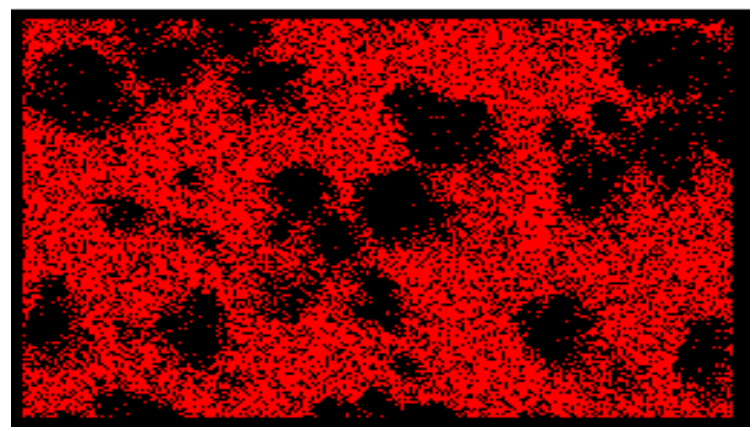

(a) Aluminium

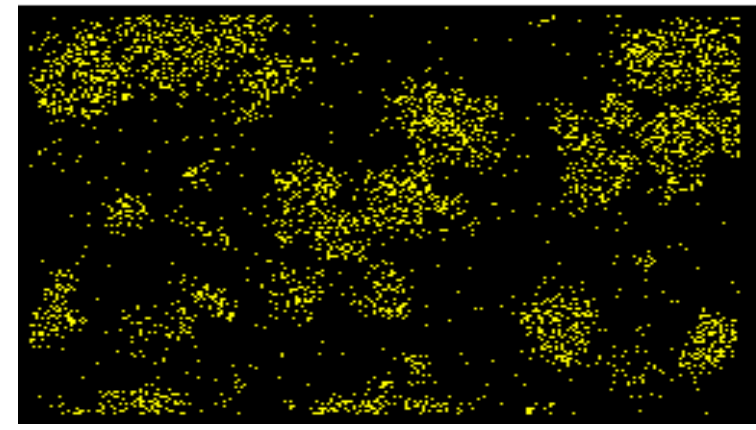

(b) Titanium

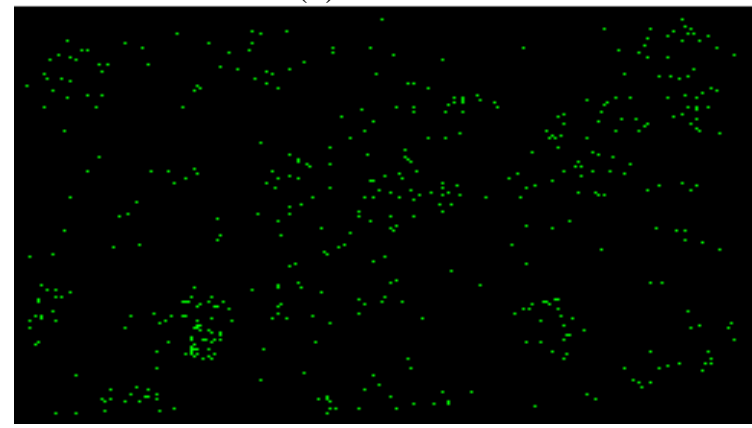

(c) Boron

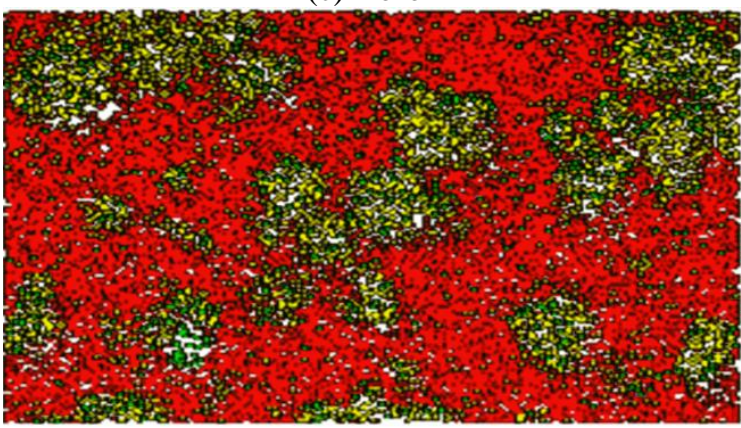

(d) Al, Ti, B all together

Figure 3. Elemental map of AA 8011- 8 Wt. \% $\mathrm{TiB}_{2}$ composite showing

\subsection{Mechanical behaviour}

The results obtained from the hardness test and tensile test of the cast AA8011, and in-situ AA8011- $\mathrm{TiB}_{2}$ composites are shown in Table 2. It is observed that the addition of titanium diboride resulted in increased hardness, in specific, the addition of 4 wt. $\% \mathrm{TiB}_{2}$ and $8 \mathrm{wt}$. $\% \mathrm{TiB}_{2}$ contributed to the increase of hardness to $21.9 \%$ and $31 \%$ from the cast AA8011. The rise in the hardness of composite is attributed to the inherent hardness property of titanium diboride and its interfacial bonding with the matrix material, which in turn enhances the deformation resistance as explained by Rengasamy et al. [27]. It is observed that the addition of titanium diboride resulted in an increased, ultimate tensile strength, in specific, the addition of 4 wt. $\% \mathrm{TiB}_{2}$ and $8 \mathrm{wt} . \%$ $\mathrm{TiB}_{2}$ contributed to $8.49 \%$ and $24.47 \%$ increase of ultimate tensile strength from that of cast AA8011. From the stressstrain curve obtained from the tensile test, as shown in Figure 4 , it is observed that a maximum tensile strength of $158.2 \mathrm{MPa}$ is obtained for the addition of $8 \mathrm{wt}$. $\% \mathrm{TiB}_{2}$. The addition of 4 wt. $\%$ of $\mathrm{TiB}_{2}$ and 8 wt. $\%$ of $\mathrm{TiB}_{2}$ of titanium diboride showed an increased percentage elongation of $44 \%$ and $38 \%$ than that of cast AA8011, and the same is depicted by the presence of increased width of strain for $4 \mathrm{wt}$. $\%$ of $\mathrm{TiB}_{2}$ compared with that of $\mathrm{AA} 8011$ and $8 \mathrm{wt} . \%$ of $\mathrm{TiB}_{2}$ in the stress-strain curve. The stress-strain curves of AA8011 and AA8011-TiB 2 
composites clearly shows three zones of deformation, namely the deformed elastic zone, uniform plastic zone and nonuniform plastic zone. The elastic limit seems to be almost common for all three materials, whereas the strain hardening region is found to be wider for 4 wt. $\%$ of $\mathrm{TiB}_{2}$ and then for 8 wt. $\%$ of $\mathrm{TiB}_{2}$ compared to cast AA8011. This shows the increase in the ability of composites to resist the deformation while subjected to loading, which is attributed to the addition of titanium diboride reinforcements. The region after the ultimate stress exposes the energy consumed before fracture, i.e., neck formation (Figure 5), which is higher for $4 \mathrm{wt}$ \% of $\mathrm{TiB}_{2}$ compared to AA8011 and AA8011-8 Wt. \% TiB 2 . The enhancement in the strength of the produced composites is ascribed to the uniform distribution of in-situ formed reinforcement and the morphology of in-situ formed titanium diboride reinforcements. Further, the in-situ formed titanium diboride has good interface bonding with the matrix. Also, it acts as a hindrance during the dislocations, which require a higher load for nucleation and void generation, as explained by elsewhere [27-29].

Table 2. Mechanical properties of cast AA8011 and in-situ AA8011-TiB 2 Composites

\begin{tabular}{cccc}
\hline Material & $\begin{array}{c}\text { Microhardness } \\
\text { Hv0.5 }\end{array}$ & $\begin{array}{c}\text { Ultimate } \\
\text { tensile strength } \\
\text { MPa }\end{array}$ & $\begin{array}{c}\text { \% } \\
\text { Elongation }\end{array}$ \\
\hline 0 & 42 & 127.1 & 5 \\
4 & 51.2 & 137.9 & 7.2 \\
8 & 55.03 & 158.2 & 6.9 \\
\hline
\end{tabular}

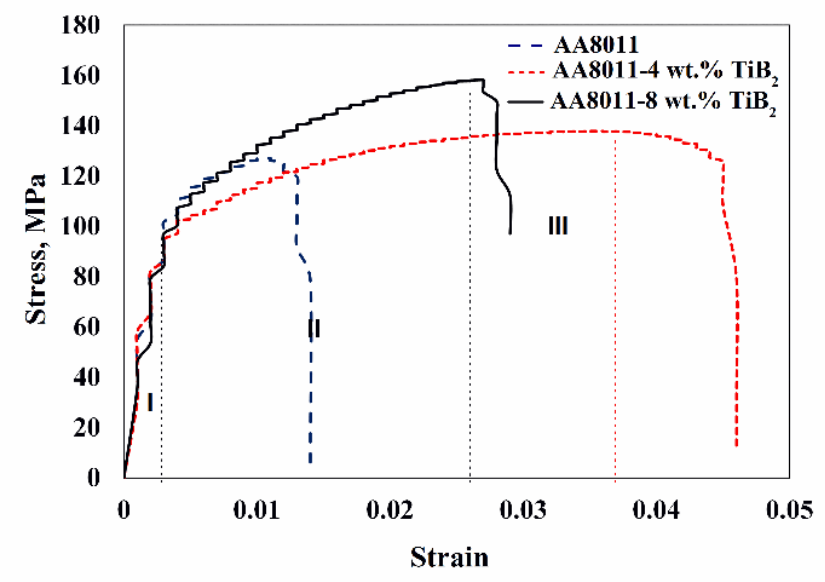

Figure 4. Stress-strain curves of AA8011 and AA8011-TiB 2 Composites

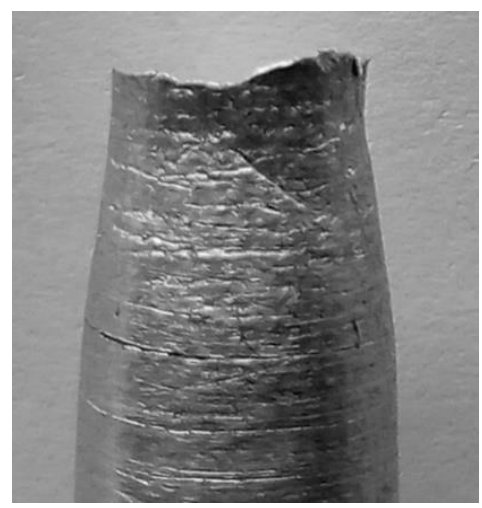

Figure 5. Neck formation observed in AA8011- 4 wt. \% $\mathrm{TiB}_{2}$

\subsection{Fractography}

The fractography of the fractured tensile samples of cast AA8011 and in-situ AA8011-TiB 2 composites used to ascertain the cause of failure is shown in Figure 6 (a-c). The fractured surface of cast AA8011 (Figure 6a) exhibits the ductile mode of failure with the existence of larger dimples along with the presence of cracks and voids. The fractured surface of AA8011-4 Wt. \% $\mathrm{TiB}_{2}$ (Figure 6b) shows the presence of medium and fine dimples which is attributed to the increase in percentage elongation of the composite that evident the improvement in the material property. The fractured surface of AA8011-8 Wt. \% $\mathrm{TiB}_{2}$ (Figure 6c) shows the presence of dimples of varied size with the clusters of fine dimples along with the reinforcement particle in the voids. The formation of coarse dimples over the fractured surface is due to the deformation of matrix metal when it is strained, and fine dimples attribute the ductile failure similar to the one reported by Suresh babu and Jayabalan [30]. Further, deep voids with larger areas are observed, which attributes to the detachment of reinforcement with the initiation and propagation of crack due to higher stress concentrations closer to the $\mathrm{TiB}_{2}$ particulates. The post-failure analysis of the fractured AA8011-4 Wt. \% $\mathrm{TiB}_{2}$ composite shows the ductile failure with the formation of fine and large dimples along with the elongated bands. Whereas for AA8011-8 Wt. \% $\mathrm{TiB}_{2}$ composite the appearance of facet failure are found to be more than that of AA8011 and AA8011-4 Wt. \% TiB 2 which attributed to a reduction in ductility.

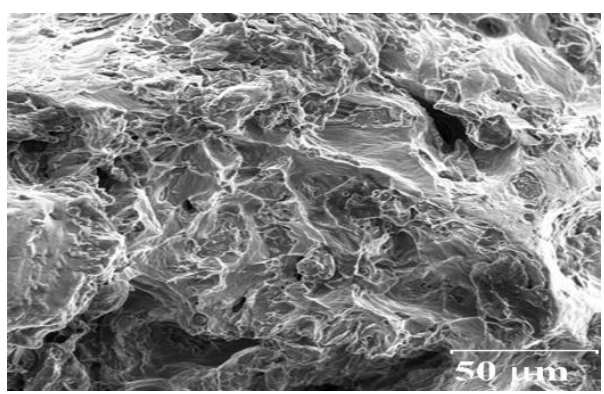

(a)

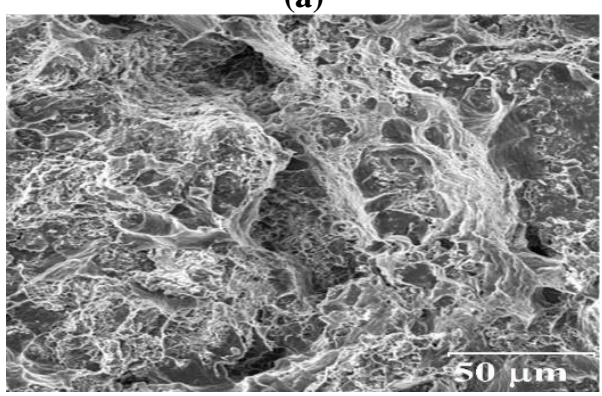

(b)

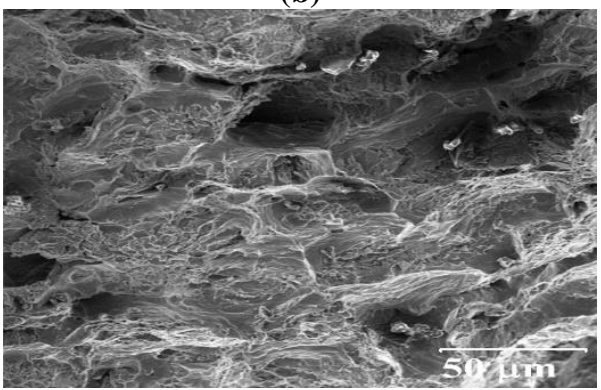

(c)

Figure 6. Fractography of (a) AA8011, (b) AA8011 - 4 Wt. $\% \mathrm{TiB}_{2}$ and (c) AA8011- 8 Wt. $\% \mathrm{TiB}_{2}$ 


\section{CONCLUSION}

In-situ aluminium alloy $8011-\mathrm{TiB}_{2}$ composites with 4 and 8 weight percentages of titanium diboride were successfully synthesized by flux assisted synthesis using stir casting technique. Formation of titanium diboride and its uniform distribution over the AA8011 matrix was confirmed using XRay Diffraction analysis and Scanning Electron Microscopic analysis with Energy Dispersive Spectroscopy. The relative density of cast AA8011 and in-situ AA8011-TiB 2 composites were found to be very close to their theoretical density. The addition of $8 \mathrm{wt} . \% \mathrm{TiB}_{2}$ resulted in a $31 \%$ increase in hardness and $24.47 \%$ increase in ultimate tensile strength. The postfailure analysis of the fractured AA8011 and in-situ AA8011$4 \mathrm{wt} . \% \mathrm{TiB}_{2}$ composite exhibited ductile failure with the formation of fine and large dimples whereas the fractured surface of AA8011-8 Wt. \% TiB2 composite exhibited more amount of facet failure, which attributed to a reduction in ductility.

\section{REFERENCES}

[1] ASM Handbook. (1991). Composites. ASM International, 1-2605.

[2] Dwivedi, S.P., Srivastava, A.K., Maurya, N.K., Sahu, R. (2020). Microstructure and mechanical behaviour of $\mathrm{Al} / \mathrm{SiC}$ /agro-waste RhA hybrid metal matrix composite. Revue des Composites et des Materiaux Avancés, 30(1): 43-47. https://doi.org/10.18280/rcma.300107

[3] Dwivedi, S.P., Srivastava, A.K., Maurya, N.K., Maurya, M. (2019). Microstructure and mechanical properties of $\mathrm{Al}$ 6061/ $/ \mathrm{Al}_{2} \mathrm{O}_{3} /$ Fly-Ash composite fabricated through stir casting. Annales de Chimie-Science des Matériaux, 43(5): 341-348. https://doi.org/10.18280/acsm.430510

[4] Magibalan, S., Senthilkumar, P., Palanivelu, R., Senthilkumar, C., Shivasankaran, N., Prabu, M. (2018). Dry sliding behavior of aluminum alloy 8011 with $12 \%$ fly ash composites. Materials Research Express, 5(5). https://doi.org/10.1088/2053-1591/aabf46

[5] Ashok, N., Shanmughasundaram, P., Ayele, N., Mulu, A. (2018). Effect of temperature, particle size, load and speed on the dry sliding wear behavior of aluminium 8011-sic composites. International Journal of Mechanical Engineering and Technology (IJMET), 9(3): 719-730

[6] Vembu, V., Ganesan, G. (2015). Heat treatment optimization for tensile properties of $8011 \mathrm{Al} / 15 \% \mathrm{SiCp}$ metal matrix composite using response surface methodology. Defence Technology, 11(4): 390-395. https://doi.org/10.1016/j.dt.2015.03.004

[7] Rao, K.V.S., Anil, K.C., Akash, Girisha, K.G. (2017) Effect of particle size on mechanical properties of AlRMp metal matrix composites. Materials Today Proceedings, $\quad 4(10)$ : 11154-11157. https://doi.org/10.1016/j.matpr.2017.08.080

[8] Shankar, B.L., Anil, K.C., Karabasappagol, P.J. (2016). A study on effect of graphite particles on tensile, hardness and machinability of aluminium 8011 matrix material. IOP Conference Series: Materials Science and Engineering, Bangalore, India. https://doi.org/10.1088/1757-899X/149/1/012060

[9] Sohi, M.H., Hojjatzadeh, S.M.H., Moosavifar, S.S., Heshmati-Manesh, S. (2014). Liquid phase surface melting of AA8011 aluminum alloy by addition of $\mathrm{Al} / \mathrm{Al}_{2} \mathrm{O}_{3}$ nano-composite powders synthesized by highenergy milling. Applied Surface Science, 313: 76-84. https://doi.org/10.1016/j.apsusc.2014.05.143

[10] Selvan, B.M.M., Anandakrishnan, V., Duraiselvam, M., Venkatraman, R., Sathish, S. (2018). Multi objective optimization of wear behaviour of in situ AA8011-ZrB metal matrix composites by using taguchi-grey analysis. Materials Science Forum, 928: 162-167. https://doi.org/10.4028/www.scientific.net/MSF.928.16 2

[11] Selvan, B.M.M., Veeramani, A. (2018). Investigation of tribological behavior of AA8011-ZrB2 in-situ castmetal-matrix composites. Materiali Technologije, 52(4): 451-457. https://doi.org/10.17222/mit.2017.046

[12] Abu-Warda, N., Utrilla, M.V., Escalera, M.D., Otero, E., López, M.D. (2018). The effect of $\mathrm{TiB}_{2}$ content on the properties of $\mathrm{AA} 6005 / \mathrm{TiB}_{2}$ nanocomposites fabricated by mechanical alloying method. Powder Technol., 328: 235-244. https://doi.org/10.1016/j.powtec.2018.01.028

[13] Meti, V.K.V., Shirur, S., Nampoothiri, J., Ravi, K.R., Siddhalingeshwar, I.G. (2018). Synthesis, characterization and mechanical properties of AA7075 based MMCs reinforced with $\mathrm{TiB}_{2}$ Particles processed through ultrasound assisted in-situ casting technique. Transactions of the Indian Institute of Metals, 71(4): 841848. https://doi.org/10.1007/s12666-017-1216-5

[14] Chen, F., Chen, Z., Mao, F., Wang, T., Cao, Z. (2015). $\mathrm{TiB}_{2}$ reinforced aluminum based in situ composites fabricated by stir casting. Materials Science and Engineering: $\quad$ A, $\quad 328$ : 235-244. https://doi.org/10.1016/j.msea.2014.12.033

[15] Kumar, G.S.P., Keshavamurthy, R., Ramesh, C.S., Bharathesh, T.P. (2015). Mechanical properties of hot forged Al6061-TiB 2 in-situ metal matrix composites. Materials Today Proceedings, 2(4-5): 3107-3115. https://doi.org/10.1016/j.matpr.2015.07.270

[16] Shen, Y., Li, X., Hong, T., Geng, J., Wang, H. (2016). Effects of $\mathrm{TiB}_{2}$ particles on microstructure and mechanical properties of an in-situ $\mathrm{TiB}_{2}-\mathrm{Al}-\mathrm{Cu}-\mathrm{Li}$ matrix composite. Materials Science and Engineering: A, 655: 265-268. https://doi.org/10.1016/j.msea.2015.12.104

[17] Rane, K., Dhokey, N. (2018). On the formation and distribution of in situ synthesized $\mathrm{TiB}_{2}$ reinforcements in cast aluminium matrix composites. Journal of $\begin{array}{lll}\text { Composites } & \text { Science, } & \text { 2(3): }\end{array}$ https://doi.org/10.3390/jcs2030052

[18] Javadi, A., Cao, C., Li, X. (2017). Manufacturing of Al$\mathrm{TiB}_{2}$ nanocomposite by flus assisted liquid state processing. Proceedia Manufacturing, 10: 531-535. https://doi.org/10.1016/j.promfg.2017.07.038

[19] Kumar, P.S., Kavimani, V., Prakash, K.S., Krishna, V.M., Kumar, G.S. (2020). Effect of $\mathrm{TiB}_{2}$ on the corrosion resistance behavior of in situ $\mathrm{Al}$ composites. International Journal of Metalcasting, 14(1): 84-91. https://doi.org/10.1007/s40962-019-00330-3

[20] Raghu, R., Nampoothiri, J., Satish Kumar, T., Subramanian, R. (2019). Microstructure and mechanical properties of $\mathrm{Al} / \mathrm{MgAl}_{2} \mathrm{O}_{4}$ in situ composites synthesized by ultrasonic cavitation. Transactions of the Indian Institute of Metals, 72(4): 1013-1021. https://doi.org/10.1007/s12666-019-01564-9

[21] Zeng, Y., Himmler, D., Randelzhofer, P., Körner, C. (2019). In situ Al3Ti/Al composites fabricated by high 
shear technology: Microstructure and mechanical properties. Materials Science and Technology, 35(18): 2294-2303.

https://doi.org/10.1080/02670836.2019.1677025

[22] Philip, S.V., Selvam, D.R.J., Rai, R.S., Mashinini, P.M. (2019). Microstructure characterization of in-situ formed $\mathrm{Al}_{2} \mathrm{O}_{3}-\mathrm{TiB}_{2}$ AMCs particles on AA6061 aluminium matrix composites. Materials Today: Proceedings, 16(2): 574-578. https://doi.org/10.1016/j.matpr.2019.05.130

[23] Narayanasamy, R., Anandakrishnan, V., Pandey, K.S. (2008). Comparison of workability strain and stress parameters of powder metallurgy steels AISI 9840 and AISI 9845 during cold upsetting. Materials \& Design, 29(10): https://doi.org/10.1016/j.matdes.2008.04.023

[24] Ilayaraja, K., Ranjith Kumar, P., Anandakrishnan, V., Sathish, S., Ravichandran, M., Ravikumar, R. (2017). Synthesis, characterization and forming behavior of hybrid copper matrix composites produced using powder metallurgy. International Journal of Materials Research, 108(7): 586-591. https://doi.org/10.3139/146.111510

[25] Ramanujam, N., Rajamuthamilselvan, M., Sathish, S. (2017). Dry sliding wear behavior of diffusion bonded AZ-91 magnesium alloy reinforced with $\mathrm{SiC}$ particles. Journal of Advances in Chemistry, 12(27): 5841-5846.

[26] Saravanan, S., Senthilkumar, P., Ravichandran, M.,
Anandakrishnan, V. (2017). Mechanical, electrical, and corrosion behavior of AA6063/TiC composites synthesized via stir casting route. Journal of Materials Research, 32(3): 606-614. https://doi.org/10.1557/jmr.2016.503

[27] Rengasamy, N.V., Rajkumar, M., Senthil Kumaran, S. (2016). Mining environment applications on Al 4032 $\mathrm{Zrb}_{2}$ and $\mathrm{Tib}_{2}$ in-situ composites. Journal of Alloys Compounds, 658: 757-773. https://doi.org/10.1016/j.jallcom.2015.10.257

[28] Ramesh, C.S., Pramod, S., Keshavamurthy, R. (2011). A study on microstructure and mechanical properties of $\mathrm{Al}$ 6061-TiB 2 in-situ composites. Materials Science and Engineering: A, 528(12): 4125-4132. https://doi.org/10.1016/j.msea.2011.02.024

[29] Yang, Y., Zhao, Y., Kai, X., Tao, R., Wang, M., Yin, H., Chen, G. (2018). Effects of $\left(\mathrm{TiB}_{2}+\mathrm{ZrB}\right)$ nanoparticles on microstructure and properties of $7055 \mathrm{Al}$ matrix composites. Materials Science and Technology, 34(11): 1323-1332. https://doi.org/10.1080/02670836.2018.1447229

[30] Babu, A.S., Jayabalan, V. (2010). Statistical analysis of the fracture strengths of aluminum alloy-alumina $\left(\mathrm{Al}_{2} \mathrm{O}_{3}\right)$ particulate composites. Journal of Materials Science, 45(24): 6586-6592. https://doi.org/10.1007/s10853-0104747-2 